\section{Nurses and advanced airway management: the experience of the Piacenza ambulance service}

\author{
Fabio Mozzarelli, Kezia Vigevani, \\ Stefano Nani, Andrea Vercelli, Enrica \\ Rossi
}

Emergency Department, Piacenza

Hospital, Italy

\section{Abstract}

The study examined the intubation manoeuvres performed by Piacenza local health authority ambulance service nurses in patients with sudden cardiac arrest of nontraumatic origin. The study has a retrospective observational design and analyzes all the intubation manoeuvres performed by ambulance service nurses in patients with non-traumatic cardiac arrest between January 2010 and December 2013. The success of the procedure with subglottic tubes was $97.7 \%$ ( $\mathrm{P}>0.60)$, while it was $100 \%(\mathrm{P}>0.50)$ with supraglottic devices. The success rate of the procedures is encouraging and the statistical analysis showed that there are no significant differences between literature data and the experience of Piacenza ambulance system crews. An increase in the use of supraglottic devices was also observed. The results show that the Piacenza ambulance service nursing staff has a good level of skills and competence in advanced airway management. A future development of this ability could involve intubation also in situations other than cardiac arrest using specific medication.

\section{Introduction}

In the field of critical patients, airway management represents a priority and fundamental phase of prehospital care. Both advanced cardiac life support (ACLS) ${ }^{1}$ and (advanced trauma life support (ATLS) ${ }^{2}$ suggest an approach as proposed by the American College of Surgeons in which phase airway (A) involves the verification, recovery and maintenance of respiratory tract patency in order to guarantee adequate oxygenation and patient ventilation.

A number of good clinical practice and caregiving guidelines have been published on advanced airway management. The Prehospital Airway Management Italian Association (PAMIA) 2010 guidelines, ${ }^{3}$ which were produced in Italy, put emphasis on certain aspects such as the indication, feasibility and opportunity of airway intervention both through tracheal intubation (TI) and extraglottic devices. They advise attempting the application of an endotracheal tube for a maximum of three attempts before considering the use of less invasive instruments such as extraglottic devices that are used when intubation is difficult due to unusual patient anatomy or injury.

These indications must be in line with the abilities, skills and experience of the operator and team. In Europe, the 2010 guidelines issued by the European Resuscitation Council (ERC) ${ }^{4}$ for patients with sudden cardiac arrest identify intubation as the gold standard and subjects undergoing the manoeuvre in emergency conditions show a significant improvement in oxygenation and other respiratory parameters. ${ }^{5}$

At an international level, the 2010 American Heart Association (AHA) guidelines for cardiopulmonary resuscitation and emergency cardiovascular care science ${ }^{6}$ guidelines stress the importance of maintaining skills through continuing training and an adequate caseload. International data indicate that $43 \%$ of cardiac arrests are subject to invasive airway management, of which $14 \%$ with an endotracheal tube and $86 \%$ with supraglottic devices. ${ }^{7}$

In Piacenza ambulance service, advanced airway management is primarily performed by the nurses on the six crews located throughout the city and surrounding province. Within this system, the medical staff on emergency vehicles has been trained to perform this manoeuvre in various different training events concerning the use of both endotracheal tubes and extraglottic devices, especially laryngeal tubes. The two methods have also been formalised through the creation of dedicated procedures contained in the institutional accreditation system.

The aim of this study was to investigate the success rate and the choice between the two methods. In order to compare homogeneous data, the authors analyzed all intubations performed by the Piacenza ambulance service nurses on patients with non-traumatic sudden cardiac arrest in extra-hospital settings between 2010 and 2013 .

\section{Materials and Methods}

The study had a retrospective design and considered the reporting of advanced airway management using endotracheal intubation and the oral extraglottic method using laryngeal tubes. It involved the pre-hospital management of patients suffering from non-traumatic sudden cardiac arrest treated by Piacenza ambulance service nursing crews.

Two teams are located in the urban area (approximately 120,000 inhabitants) and trav-
Correspondence: Fabio Mozzarelli, Emergency Department, Piacenza Hospital, via Antonio Anguissola n.15, Piacenza, Italy.

Tel/Fax: +39.0523.301111.

E-mail: fabio.mozzarelli@Gmail.com

Contributions: FM took care of data processing and drafting of the article; KV and SN collected data; $\mathrm{AV}$ and ER critically processed data.

Conflict of interest: the authors declare no potential conflict of interest.

Key words: Intubation; Supraglottic devices; Endotracheal tubes; Nurses.

Received for publication: 7 February 2015. Revision received: 28 April 2015. Accepted for publication: 11 April 2015

This work is licensed under a Creative Commons Attribution 3.0 License (by-nc 3.0)

(C) Copyright F. Mozzarelli et al., 2015 Licensee PAGEPress, Italy

Emergency Care Journal 2015; 11:5089

doi:10.4081/ecj.2015.5089

el by medical/nursing cars and ambulance. Four teams work throughout the rest of the province (170,000 inhabitants), of which one with a nursing car and the other by ambulance. The period considered in this study was between 01/01/2010 and 31/12/2013. Patients intubated by doctors, trauma patients, those in a coma and patients who were found in or evolved toward cardiocirculatory arrest but were ventilated with non-invasive methods were excluded from the study.

The emergency service nurses had all been trained on airway management in special training events including practical work on patient simulators and also, on occasions, in the operating theater.

In line with the requirements of the regional accreditation model, airway management was allocated the clinical competence of the ambulance service and the various professional figures were stratified into four levels in line with their skill sets. ${ }^{8}$ The first stage concerned professionals with modest skills or those who were still training, the second concerned skilled nurses, the third expert operators, and the fourth very expert professionals able to train others.

In the method considered, the nurses were allowed the freedom to decide whether to manage the patient by TI or extraglottic device. The decision depended primarily on the operator's skill and the conditions of the patient in terms of the expected difficulty in obtaining a patent airway.

Data was recorded on a dedicated form (Table 1) in which, in addition to providing 
his/her personal details, the professional nurse also indicated the type of intubation. Correct device application was ascertained and recorded on the form by the ambulance service doctor when one subsequently arrived on the scene of the event and by a Piacenza local health authority emergency service doctor if the subject was taken to hospital. On the contrary, if death was confirmed on site, the healthcare continuity doctor or general practitioner evaluated the outcome of the method used. The forms are stored in the headquarters of the Piacenza ambulance service.

\section{Statistical analysis}

For statistical analysis, the study population consisted of all patients with non-traumatic sudden cardiac arrest who underwent advanced airway management by a local emergency medical service nurse. Frequency distributions were calculated as percentages. Arithmetic mean $\left(\mathrm{M}_{\mathrm{a}}\right)$ and standard deviation $( \pm \mathrm{SD})$ were used for central tendency measurements. Categorical variable analysis was performed using the chi-square test. Statistical significance was expressed with $\mathrm{P}<0.05$.

The primary outcome was therefore correct tube positioning, whereas the secondary outcome concerned the recording of the number of applications and the type of instrument used. The data were processed using Microsoft ${ }^{\circledR}$ Office Excel 2003.

\section{Results}

The observation period was between January 2010 and December 2013. Over this period of time, a total of 221 subjects underwent sub- or supraglottic intubation by the Piacenza provincial emergency medical service nurses, as shown in Figure 1. Eligible subjects were all non-traumatic cardiac arrest patients undergoing advanced airway management, in total 209 (94.5\%). Table 2 shows the main characteristics of the study population.

Of the above patients, 180 (86\%) underwent tracheal intubation via the oral route, which was successful in 176 cases (97.7\%) as shown in Figure $2(\mathrm{P}>0.60)$. In the $29(14 \%)$ subjects treated with a laryngeal tube, the procedure was performed successfully in all 29 cases $(100 \%)$, as summarised in Figure $3(\mathrm{P}>0.50)$.

\section{Discussion}

The results of the study provided an exhaustive picture of the advanced airway management situation. The results concerning the success rate for device application are particu-
Table 1. Form for intubation database record.

\section{Answers}

Name (nurse)

Surname (nurse)

Date of intubation

\begin{tabular}{llll} 
Intubation type & TI-LTI & LMI & Other \\
\hline Outcome of intubation & Positive & Negative &
\end{tabular}

Medication

Ambulance sevice tag

Certifying doctor

Progressive number

TI LTI, tracheal intubation-laryngoscopy and tracheal intubation; LMI, laryngeal mask insertion.

Table 2. Patients' basic characteristics.

\begin{tabular}{lcc} 
& N & $\%$ \\
Gender & - & 50.2 (females); 49.8 (males) \\
Defibrillatable cardiac arrest* $^{*}$ & 13 & 6.20 \\
Non-defibrillatable cardiac arrest $^{\circ}$ & 196 & 93.70 \\
Died on site $^{\circ}$ & 141 & 67.40 \\
\hline Died in the emergency department & 57 & 27.20 \\
Admitted to general intensive care & 8 & 3.80 \\
\hline Admitted to coronary intensive care & 3 & 1.60 \\
\hline
\end{tabular}

Mean age was $71.9 \pm 5.6$ standard deviation. *Ventricular fibrillation-pulseless ventricular tachycardia; ${ }^{\circ}$ asystolia-pulseless electrical activity.

\begin{tabular}{|c|}
\hline adv \\
\hline $\begin{array}{l}\text { 209: Non-traumatic } \\
\text { cardiac arrest } \\
\text { patients intubated } \\
\text { using supra- or } \\
\text { subglottic devices } \\
\text { by Ambulance } \\
\text { Service nurses }\end{array}$ \\
\hline
\end{tabular}

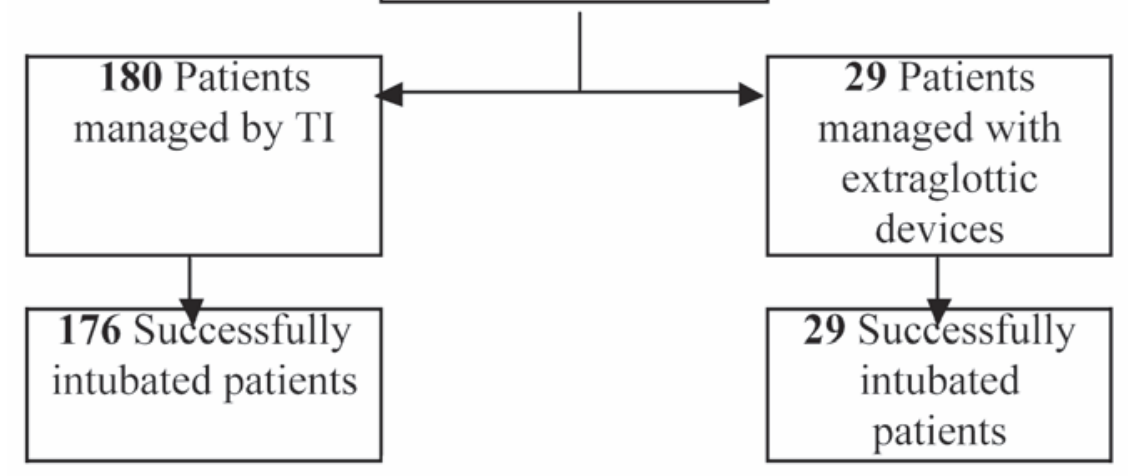

Figure 1. Study profile. 
larly interesting in that they are better than those reported in literature. It should be noted that all laryngeal tubes were positioned correctly.

The data analysis provides non-statistically significant values, highlighting the absence of differences between the elements recorded and the scientific references adopted.

We can also see that during the study period there was a constant increase in the use of the rent your tubes, as shown in Figure 4.

It is unknown whether this depends on the difficulties estimated by the operator before performing the manoeuvre, or by training events that developed extraglottic device application skills, or to the rapidity and ease-of-use of these devices.

As regards this latter aspect, scientific literature contains plenty of publications emphasising their favorable properties. A number of scientific articles were found in the literature review, such as one study conducted in Canada evaluating the success of intubation performed by paramedics without medication in patients with a Glasgow Coma Scale score of 3 . The authors obtained results that were inferior to those collected in the other studies considered and therefore concluded by stressing the need for better training. ${ }^{9}$ Another article concluded that in cardiac arrest patients airway management with endotracheal tubes remains the most appropriate choice..$^{10}$ Intubation was compared with the use of extraglottic devices, and while some authors believe the latter to be more efficacious, ${ }^{11}$ others claim they cannot be considered superior to the more invasive methods, but represent a valid alternative to TI. ${ }^{12-14}$ Other researchers did not find any difference between the two methods in terms of the neurological outcomes of patients surviving the sudden cardiac arrest. ${ }^{15}$ According to certain researchers, the different methods of basic and advanced airway management are not related to patient survival and post-anoxia consequences. ${ }^{7,16,17}$

The weak points in this study's design (retrospective) is characterised by a number of intrinsic limitations, i.e. it is only possible to process data already collected. The intubation record sheets did not include the time required to position the device chosen and the number of attempts required. Moreover, there could be information bias as both the person collecting the data and the one processing it knew the operators who performed the manoeuvres.

All episodes of invasive airway management were systematically recorded throughout the Piacenza area. Correct device positioning was confirmed by doctors who had not been involved in the life-support manoeuvres and were therefore neutral in relation to the nurses who performed intubation.

\section{Conclusions}

The recording of data concerning sub- and supraglottic intubation showed that both methods chosen by the Piacenza ambulance service were fully successful.

The results obtained with the regular application of endotracheal (97.7\%) and laryngeal (100\%) tubes are particularly comforting considering that in emergency airway management scientific results reveal that $5.3 \%$ of manoeuvres are considered as difficult intubations, ${ }^{18}$ and of these $0.05 \%$ of patients cannot be intubated or ventilated. ${ }^{19}$

Nevertheless, the training system for the method considered proved to be extremely

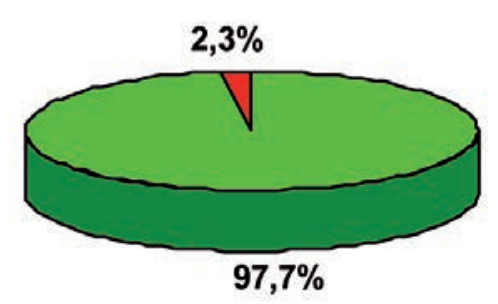

effective. As indicated in the specific requirements of the institutional accreditation system, the minimum invasive airway management expected of local emergency service nurses concerns the use of supraglottic devices. ${ }^{18}$

Remaining within the context of regional certification, it could be appropriate to divide the various professional figures into their corresponding skill levels. The first and second grades could be expected to be skilled in the use of extraglottic devices, whereas the following two classes could be expected to perform TI correctly.

Given the good results obtained, the use of medication could be considered in order to favor tracheal intubation manoeuvres also in

Figure 2. Outcomes of endotracheal intubation.

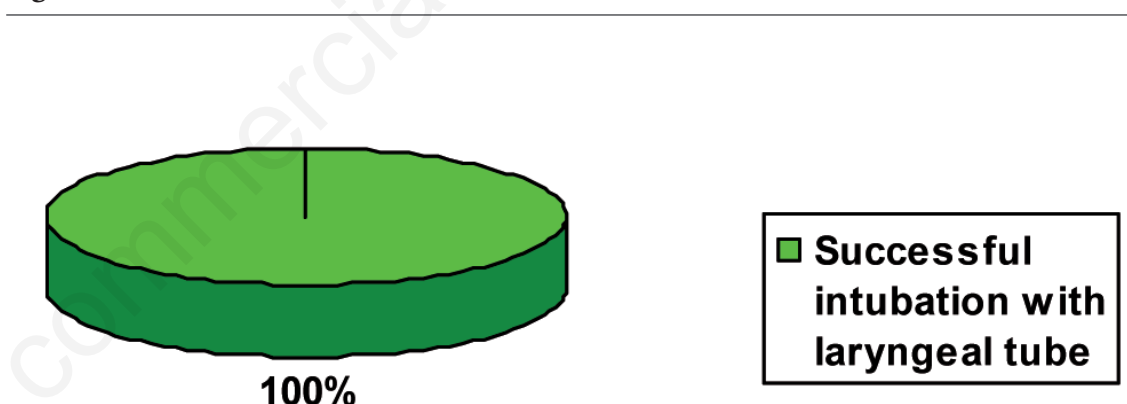

Figure 3. Outcomes of laryngeal tube intubation.

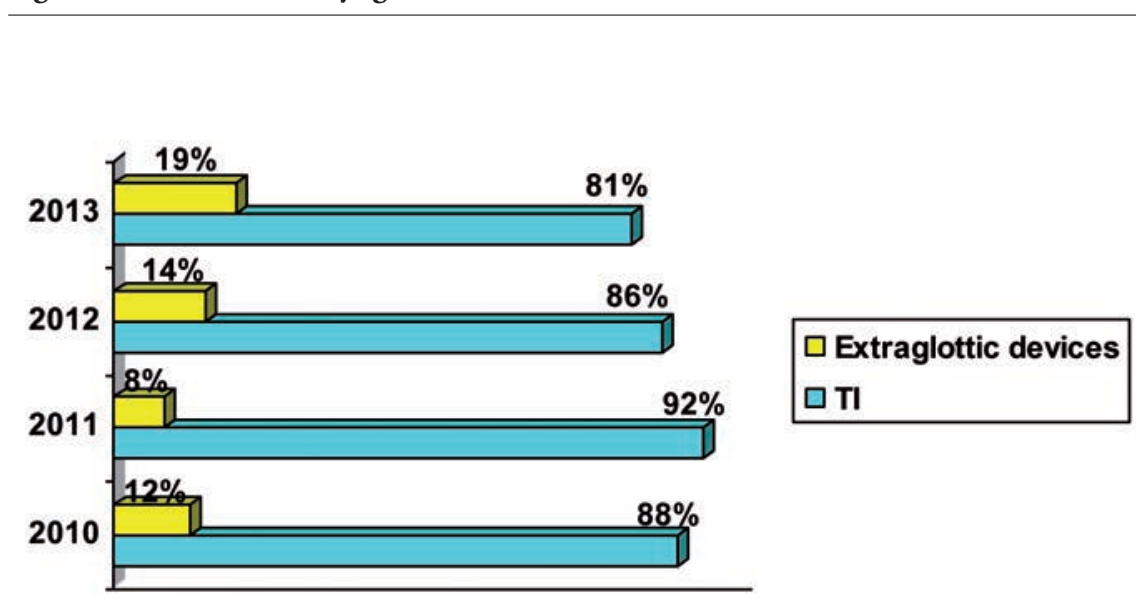

Figure 4. Tracheal intubation:extraglottic device ratio.

$\square$ Successful manoeuvre

Unsuccessful manoeuvre 
patients presenting reflexes and resistance, such as for example patients with post-traumatic conditions. As suggested by certain papers, the use of opioids and benzodiazepines could be suited to the above. ${ }^{20}$ These medicinal products are easy to use as they can be readily displaced by their corresponding antagonists if adverse events occur. In connection with this, the Piacenza ambulance service recently developed a specific care procedure.

\section{References}

1. American Heart Association. Advanced cardiac life support. Dallas, TX, USA: American Heart Association; 2010.

2. American College of Surgeons Committee on Trauma. Advanced trauma life support. 9th ed. American College of Surgeons Committee on Trauma: Chicago, IL, USA; 2012.

3. Prehospital Airway Management Italian Association. Guidelines for the management of prehospital airway. Bologna, Italy: Prehospital Airway Management Italian Association; 2010.

4. European Resuscitation Council. Guidelines for advanced cardiac life 2010. Available from: www.cprguidelines. eu/2010/

5. Gonsaga RA, Valiatti JL, Brugugnolli ID, et al. Evaluation of gasometric parameters in trauma patients during mobile prehospital care. Rev Col Bras Cir 2013;40:293-9.

6. American Heart Association. Guidelines for cardiopulmonary resuscitation and emergency cardiovascular care science 2010. Available from: http://circ.ahajournals.org/content/122/18_suppl_3/S729.full

7. Hasegawa K, Hiraide A, Chang Y, Brown DF. Association of prehospital advanced airway management with neurologic outcome and survival in patients with out-ofhospital cardiac arrest. J Am Med Assoc 2013;6:257-66.

8. Regione Emilia/Romagna. Requisiti specifici per l'accreditamento delle Strutture di Emergenza e Urgenza Regione Emilia/Romagna. Delibera Giunta Regionale $\mathrm{n}^{\circ} 23$ 17/01/2005. Available from://assr.regione.emilia-romagna. it/it/servizi/pubblicazioni/legislazione-eatti-amministrativi/requisiti-accreditamento/requisiti-specifici

9. Tam RK, Maloney J, Gaboury I, et al. Review of endotracheal intubations by Ottawa advanced care paramedics in Canada. Prehosp Emerg Care 2009;13:3115.

10. Goldberg SA, Metzger JC, Pepe PE. Year in review 2011: critical care. Out-of-hospital cardiac arrest and trauma. Crit Care 2012;16:247.

11. Duckett J, Fell P, Han K, et al. Introduction of the i-gel supraglottic airway device for prehospital airway management in UK ambulance service. Emerg Med J 2014;31: 505-7.

12. Lyon RM, Ferris JD, Young DM, et al. Field intubation of cardiac arrest patients: a dying art? Emerg Med J 2010;27:321-3.

13. Sunde GA, Brattebo G, Odegarden T, et al. Laryngeal tube use in out-of-hospital cardiac arrest by paramedics in Norway.
Scand J Trauma Resusc Emerg Med 2012; 18:20-84.

14. Muller JU, Semmel T, Stepan R, et al. The use of laryngeal tube disposable by paramedics during out-of-hospital cardiac arrest: a prospectively observational study (2008-2012). Emerg Med J 2013;30:1012-6.

15. Tanabe S, Ogawa T, Akahane M, et al. Comparison of neurological outcome between tracheal intubation and supraglottic airway device insertion of out-ofhospital cardiac arrest patients: a nationwide, population-based, observational study. J Emerg Med 2013;44:289-97.

16. Hanif MA, Kaji AH, Niemann JT. Advanced airway management does not improve outcome of out-of hospital cardiac arrest. Acad Emerg Med 2010;17:926-31.

17. Egly J, Custodio D, Bishop N, et al. Assessing the impact of prehospital intubation on survival in out-of-hospital cardiac arrest. Prehosp Emerg Care 2011;15:44-9.

18. Petrini F, Rosafio T. The airway management in emergency. Available from: http://rianimazione.net/node/483

19. Agrò F, Amicucci G, Azzimonti G, et al. SIAARTI guidelines for difficult intubation and the difficulty of management. Available from: http://anestit.unipa.it/ siaarti/Intubazing.htm

20. Cushman JT, Zachary Hettinger A, Farney A, Shah MN. Effect of intensive physician oversight on a prehospital rapid-sequence intubation program. Prehosp Emerg Care 2010;14:310-6. 